INTERNATIONAL JOURNAL OF MULTidisciplinARY RESEARCH AND ANALYSis

ISSN(print): 2643-9840, ISSN(online): 2643-9875

Volume 05 Issue 02 February 2022

DOI: 10.47191/ijmra/v5-i2-25, Impact Factor: 6.072

Page No. $410-413$

\title{
An Analysis of Traditional Chinese Patterns in Arts and Crafts
}

\author{
Gao Yiying \\ Silpakorn University
}

ABSTRACT: A brief analysis of the relationship between art and life through the presentation and development of traditional patterns on different utensils. In the four major sections of pottery, bronze ware, clothing and arts and crafts, relevant explanations are given on the application of traditional patterns. The diversity of traditional patterns starts from the level of cultural development, and plays a key role in the impact on people's life development and the inheritance, promotion and integration of traditional culture. Through the study and understanding of patterns, we can discover the inclusiveness of art and people, art and culture.

KEY WORDS: Chinese traditional patterns; decorative arts; arts and crafts

\section{THE DEVELOPMENT PROCESS OF TRADITIONAL CHINESE PATTERNS}

\subsection{Display of traditional patterns on pottery}

Throughout history, painted pottery of various regional cultures has different styles, shapes and colors. Pottery first appeared because of the needs of human beings for production and life. As time goes by, people's artistic aesthetic awareness gradually improved, then they began to draw patterns on these pottery. The pottery of the Yangshao Culture period has appeared with traditional Chinese patterns, which is an important cultural sign. The pottery is embellished with exquisite and meticulous patterns, especially the appearance of painted pottery has brought a variety of traditional patterns to display. China's Banpo type, Majiayao type, Miaodigou type, etc. have various distinctive Chinese patterns. The diversity of its decorative techniques makes each pattern have a different meaning. For example, the painted pottery patterns of Banpo type are mainly geometric patterns, including wide band patterns, diamond patterns and some linear patterns. These patterns are rich in rhythm, regular in arrangement, and have certain decorative elements with a sense of order. The style is simple and not pretentious, representing the exploration and recording of the real world.Fish-shaped pattern is one of the distinctive traditional patterns (As shown in Figure 1), The fish pattern was originally a figurative pattern, and then gradually became a simple geometric pattern, and the number of paintings on the pottery also changed from the earliest one to many.The same is true for human face patterns. The simple lines and stripes on the human face and the fish-shaped patterns are combined into one, forming a new pattern. The pattern is unique, and the pattern is given special meaning. It is full of associations with the artistic conception of heaven and earth.

\subsection{The historical origin of patterns and bronzes}

Bronze ware is one of China's splendid cultures, closely related to human social life, showing the rapid development of smelting technology in Chinese society at that time. Most of the decorative patterns of bronze wares in the Shang Dynasty were related to sacrifices, and most of the patterns were created by imagination.The bronze patterns cast and portrayed on bronze ware are also constantly changing with the development of culture. From the initial admiration for the gods, with the development of time, they are gradually related to real life.The decorative patterns of the early bronzes were mostly people and animals. Although the patterns were simple, they were somewhat rough.In the mid-term, with the gradual improvement of bronze smelting technology, bronze patterns were refined and beautiful, and multi-layer pattern decoration began. Symmetrical patterns and Fret patterns appeared, which formed a comparative relationship with the main patterns.There are two kinds of animal patterns in the Shang Dynasty, one is a real animal, and the other is a mythical beast with a specific meaning imagined by people.The Shang Dynasty was an era in which monarchical power was granted by gods and the political concept of destiny and divine power, so the 


\section{An Analysis of Traditional Chinese Patterns in Arts and Crafts}

second pattern was more common in its decoration (As shown in Figure 2).The main utensils used for sacrifice in the Shang Dynasty were made of bronze, and the meaning of these traditional patterns is also related to it. For example, the dragon pattern is one of the traditional patterns which has been used the most and the longest. Compared with nowadays, the dragon pattern at that time was a pattern that was added and merged to almost become a deified pattern, with auspicious and beautiful meanings.

\subsection{Application of traditional patterns on clothing}

Clothing is an indispensable necessities in people's life. China is the first country to use silk as clothing. With the progress of the times, people's requirements for silk fabrics have gradually increased, and the styles of demand are also diverse.There are many and complex patterns in Chinese clothing art, and the craftsmanship styles are also completely different. Brocade and Embroidery, as the splendid crafts, these two main methods are from the costume art of the Han Dynasty.The original clothing patterns were widely used in embroidery patterns of plants and animals, mostly dogwood patterns. With the development of the times, people wisely embroider the text representing the meaning on the clothing silk to form a unique text pattern. This type of text pattern has become more common in the western region of China, and clothing with text patterns has formed a special Chinese clothing cultural phenomenon and has become a carrier for the development and dissemination of traditional culture.

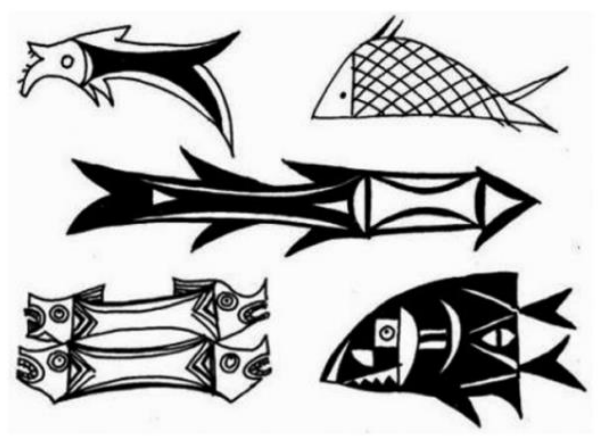

Figure 1.Fish-shaped pattern

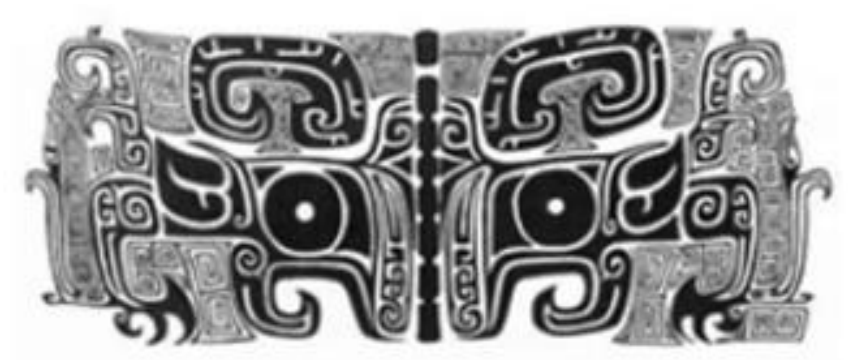

Figure 2. Shang Dynasty bronze pattern

\section{THE FUSION OF TRADITIONAL CHINESE PATTERNS AND DECORATIVE ARTS}

The emergence of decorative art is indispensable, which is a manifestation of human aesthetic consciousness and the perception and understanding of life.For thousands of years, the works of Chinese arts and crafts have been widely known, and the traditional patterns on them are even more exquisitely decorated. These traditional patterns are preserved in the world with their own lines and tell the charm of ancient Chinese culture.This is a method of combining the beauty of art with the senses. It is a design that meets the needs of social development at that time. This design is integrated into life, giving them shapes and colors, and presenting human behavior in an artistic way. It is transformed into art culture with a special method, and a more interesting civilization culture is formed through the perception of beauty in art, so that human life is full of decorative colors, Improve human needs for quality of life and the impact of psychological value.The arrangement of patterns, coupled with various expression methods and techniques such as rhythm, composition, patchwork, symmetry, etc., are integrated into a new decorative art with aesthetic awareness.

Artistic creation is the liberation of human nature. The traditional Chinese decorative art of patterns was produced a long time ago. The formation of each thing is related to specific conditions and environments, and is full of the combination of necessity and chance.So how did the word "pattern" come about? There are many speculations about this issue. Some people think that the patterns on the artifacts were discovered accidentally by humans. Later, people innovated into decorative patterns, and refined 


\section{An Analysis of Traditional Chinese Patterns in Arts and Crafts}

and beautified them again and again and gradually became the mature traditional patterns.In primitive tribes, cavemen will use some ordinary natural small objects to decorate and embellish them, and some will also color them to make them beautiful.These patterns are endowed with a variety of decorative art meanings, representing the ancestors' yearning for a better life and their exploration and recording of the real world. Using different expressions to explain, from simple to complex, from image to specific, from single color to colorful decorative patterns, etc., the human artistic thought form has changed from being bound to creating in a unique visual form.Decorative art has always adjusted the boring and uninteresting life of human beings in the past with its special modeling techniques, making life full of artistic flavor and beautiful enjoyment, making people relax and taste in an artistic form. It connects the patterns, decoration and culture in traditional art.

\section{THE DIVERSITY OF CHINESE TRADITIONAL PATTERNS}

\subsection{Patterns of single style}

The pattern of a single pattern refers to the main pattern on the utensil as an independent form of expression, specifically using a pattern to express the interpretation of the beautiful meaning on the utensil.The use of this pattern will be more stringent in terms of point, line, and surface requirements, and in the process of drawing, it needs to be adapted to the shape, color, size and other factors of the object to be drawn.In use, it should cooperate with the utensils and complement each other to avoid a series of problems caused by the inconsistent effect of pattern decoration. The more common composition methods of a single pattern are mainly asymmetric and symmetrical. Symmetrical composition brings people a comfortable feeling (As shown in Figure 3), while asymmetrical composition is more flexible (As shown in Figure 4).The use of cloud patterns is mostly asymmetrical patterns, most of which are delicate and diverse, and the styles are also much richer and more different.

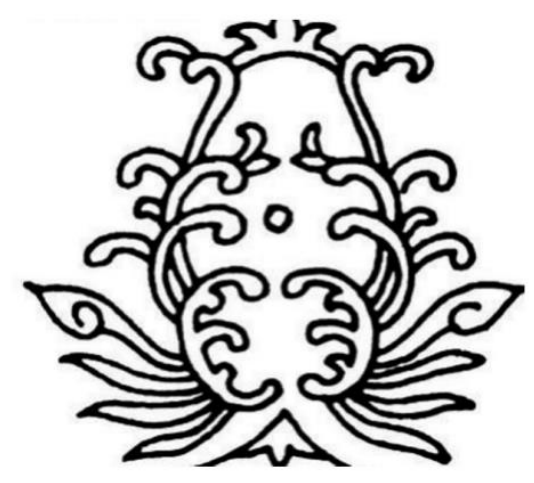

Figure 3. symmetrical plant pattern

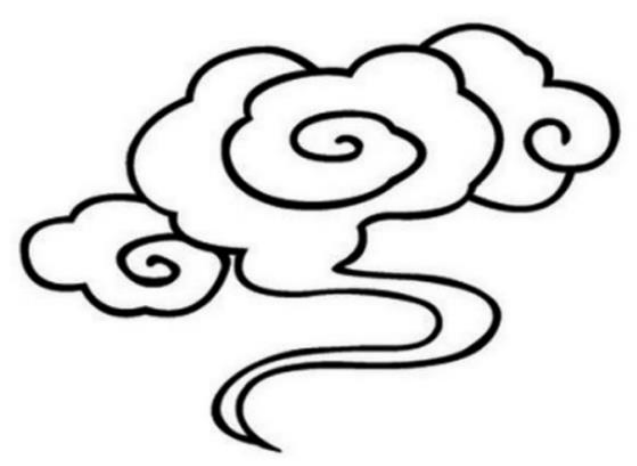

Figure 4. asymmetrical cloud pattern

\subsection{Continuity of patterns}

Continuous patterns in the utensils and clothing, mostly one pattern is drawn continuously for many times, with a sense of order.The continuous pattern will be more substantial and rich in composition, which is mainly suitable for a wide range of main decorations.As shown in Figure 5, the fret pattern is a typical continuous pattern, which is formed by seamlessly connecting a group of patterns similar to the Fret in multiple groups, with regularity and uniformity.The application of Fret pattern has a long history, from the early painted pottery to bronze, and is still being used until now. There are many such common patterns, such as 


\section{An Analysis of Traditional Chinese Patterns in Arts and Crafts}

water patterns, weaving patterns, etc.Such a composition effect is neat, the decorative effect is more obvious, and it brings a different feeling from a single pattern pattern.

\subsection{Plane line of sight pattern}

The composition form of the plane line of sight pattern is full and complete, occupying a major position on the whole, and can fully show the content and ideas that you want to express in the picture. It is widely used in the depiction of scenes. It is divided into one or several parts in an orderly manner from a head-up perspective. Each part expresses different meanings of patterns, although the content in different parts is different. But they will form a new unity and feeling with each other, which is interesting. Its composition method is different from that in the early days, and it can better show the life at that time. As shown in Figure 6 , the decorative scene depicted on the Yanle copper pot is a pattern using a plane perspective. Each part expresses different content, and the composition effect is complete and unconstrained, and each has its own characteristics.

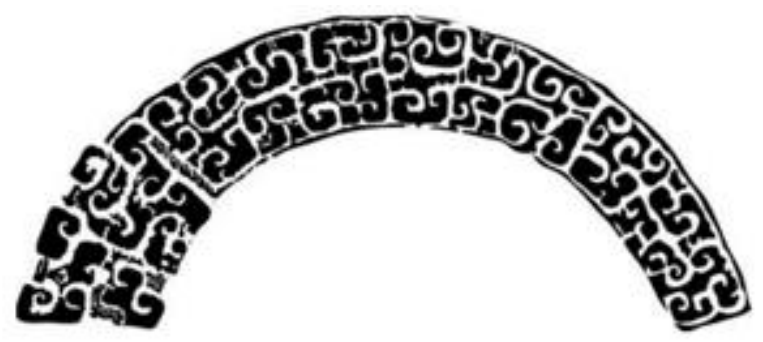

Figure 5.Continuous Fret pattern

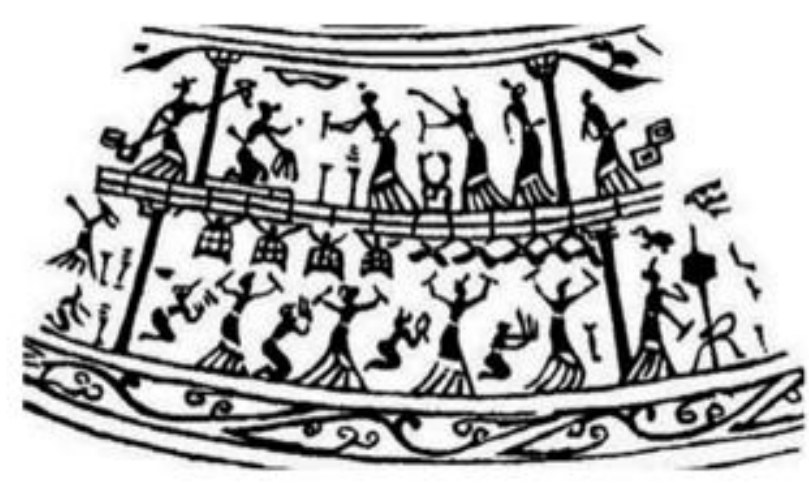

Figure 6. "yanle"Copper kettle

Chinese traditional patterns are one of the representatives of traditional culture. The purpose of analyzing the significance of Chinese traditional patterns in arts and crafts is to spread the ancient Chinese culture, understand the creation methods and wisdom of ancestors, and get some inspiration from it. In modern society, the development of patterns requires us to adopt innovative methods to inherit, extract the refined elements for creation, obtain a new way of expression, and use them flexibly.

\section{REFERENCES}

1) You J. Analysis of traditional culture in graphic design. China National Expo 2018; 01: 162-163.

2) Huilong Tian An Analysis of the Innovative Performance of Traditional Patterns in Modern Design [J] Advances in Higher Education,2020

3) An Analysis of the Innovative Performance of Traditional Patterns in Modern Design.[J]Advances in Higher Education Volume 4, Issue 5. 2020.

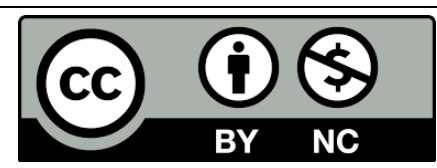

There is an Open Access article, distributed under the term of the Creative Commons Attribution - Non Commercial 4.0 International (CC BY-NC 4.0)

(https://creativecommons.org/licenses/by-nc/4.0/), which permits remixing, adapting and building upon the work for non-commercial use, provided the original work is properly cited. 